\title{
LAZER, ENVELHECIMENTO E PARTICIPAÇÃO SOCIAL ${ }^{1}$
}

Recebido em: 22/06/2011

Aceito em: 03/02/2012

\author{
José Alfredo Oliveira Debortoli ${ }^{2}$ \\ Universidade Federal de Minas Gerais - UFMG \\ Belo Horizonte - MG - Brasil
}

RESUMO: Proponho uma reflexão sobre a temática do Lazer buscando uma discussão que entrelace as noções de velhice, de envelhecimento e de participação social. $\mathrm{O}$ sentido de social anunciado se alinha à concepção proposta pelo antropólogo inglês Tim Ingold (2011, p.44), em que a vida social não está cindida em um plano separado da natureza, mas constituída como uma textura em que se revelam contextos, práticas e relações. A noção de envelhecimento é anunciada como uma condição de estar vivo. $\mathrm{O}$ Lazer, mais que um conceito ou objeto, é tomado como um processo, como uma maneira de viver, enfatizando a arte, o corpo, a co-responsabilidade e sensibilidade com a vida e com o mundo na centralidade das relações. Anuncio uma reflexão sobre as práticas de Lazer estabelecendo relações com os diferentes tempos da vida, em especial, compreendendo a jornada de vida reconhecida como percurso de desenvolvimento, de sabedoria, de constituição de habilidades de viver.

PALAVRAS CHAVE: Atividades de Lazer. Envelhecimento. Participação Social.

\section{LEISURE, GROWING OLD AND SOCIAL PARTICIPATION}

ABSTRACT: I propose a reflection on the theme of leisure seeking a discussion that interlace the notions of old age, growing old and social participation. The sense of social advertised aligns the design proposed by British anthropologist Tim Ingold (2011, p.44), in which social life is not split into a separate plan of nature, but formed as a texture in which they reveal contexts, practices and relationships. The notion of aging is advertised as a condition of being alive. The Leisure more than a concept or object is taken as a process, as a wayfaring, emphasizing the art, the body, co-responsibility and sensitivity to the life and the centrality of relationships in the world. Announce a reflection on the practices of Leisure establishing relations with the different times of life, in particular, understanding the journey of life recognized as a development path of wisdom, the formation of life skills.

\footnotetext{
${ }^{1}$ Este texto foi produzido como roteiro de aula ministrada em 2011, no Projeto Universidade Aberta à Terceira Idade, da EEFFTO/UFMG, coordenado pela Professora Marcela Tirado.

${ }^{2}$ Professor EEFFTO/UFMG e Pesquisador Coolaborador - DAN/UnB.
} 


\section{KEYWORDS: Leisure Activities. Aging. Social Participation.}

Eu preparo uma canção em que minha mãe se reconheça.

Todas as mães se reconheçam

E que fale como dois olhos.

Caminho por uma rua que passa em muitos países.

Se não me vêem eu vejo e saúdo velhos amigos.

$\mathrm{Eu}$ distribuo um segredo como quem anda ou sorri

No jeito mais natural

Dois carinhos se procuram.

Minha vida, nossas vidas formam um só diamante.

Encontrei novas palavras e tornei outras mais belas.

Eu preparo uma canção que faça acordar os homens

E adormecer as crianças.

Carlos Drummond de Andrade

\section{Introdução}

Proponho uma reflexão sobre a temática do Lazer tomando como perspectiva de análise a busca de caminhos possíveis para concebermos uma formação humana que se realiza como jornada de vida, que é institucional, mas, sobretudo, cotidiana e relacional. Provoco uma atenção e uma reflexão sobre nossa condição humana, que se realiza de forma encarnada como experiência, narrativa, transformação, produção do mundo e de si mesmo: como prática, processo e relação.

Com essa concepção, a discussão sobre a velhice se justifica de forma relacional e a problematização das formas de participação social requer pensar uma riqueza de processos de envolvimento social. Por isso, o sentido do social, aqui anunciado, expressa uma abordagem ecológica, como propõe Ingold (2011, p.44), em que a vida social não está cindida em um plano separado da natureza, mas constituída como uma textura em que se revelam contextos e relações em que todos nós habitamos, caminhamos e nos co-responsabilizamos; ou como propõe Leonardo Boff (1997, p. 191), atento às "relações que todos os seres vivos e inertes mantêm entre si e com o 
meio ambiente", habitando essa "casa comum que precisa ser preservada: nosso planeta Terra”.

A noção de envelhecimento é anunciada como um percurso de vida, como uma condição de estar vivo. O Lazer, mais que um conceito ou objeto, é tomado como um processo, como uma maneira de viver, subvertendo uma lógica objetivada e instrumental da modernidade, que toma o Lazer como experiência social secundária, compensatória ou projeto de futuro. Ao contrário, para compreender a prática social, proponho enfatizar a arte, o corpo, a co-responsabilidade e sensibilidade com a vida e com o mundo na centralidade das relações.

Nesse sentido, pensar a velhice supõe reconhecer a vida como um processo que entrelaça a todos como crianças-jovens-velhos, constituindo percursos de partilha da vida, bem como com tudo que nos envolve. O velho não é o outro do jovem ou da criança, mas uma expressão de nossa condição humana total e universal.

De certo, abordar o tema do envelhecimento é um grande desafio, tanto pela sua riqueza quanto pelas tensões que provoca e nos provoca ampliar as possibilidades do viver. Instiga-nos também pelo conjunto de representações que o atravessa; e produz percepções de si mesmo e da vida, na maior parte das vezes com um sentido de negatividade. Buscando outras formas de narrativa, procuro, entretanto, ir ao encontro da beleza e da poesia que a vida reclama, expressa e revela; atento para não cair nas armadilhas de uma visão romantizada da vida e das pessoas.

Nesse sentido, proponho provocar um entendimento de que a produção de um olhar sobre a vida e as relações é, também, no sentido de Walter Benjamin (1987), uma questão de aposta na condição humana, estabelecendo menos importância a uma perspectiva de limitação; mas desafiando possibilidades de nos constituirmos com 
beleza, sabedoria e delicadeza.

Anuncio, pois, uma reflexão sobre as práticas de Lazer estabelecendo relações com os diferentes tempos da vida, em especial, compreendendo a jornada de vida como um processo inevitável de envelhecimento, que também pode ser reconhecido como percurso de desenvolvimento, de sabedoria, de constituição de habilidades de viver. Ser velho-jovem-criança como uma totalidade capaz de inspirar uma prática-narrativa de vida como experiência-lembrança de nossas transformações e dos aprendizados permanentes e necessários das formas de viver.

\section{Entre práticas, signos e sentidos: "brincando" com as palavras.}

As formas de nomear a velhice se revelam em práticas sociais, provocando-nos refletir, especialmente, sobre noções objetivadas das relações sociais, entre elas, as experiências de Lazer. A vida social contemporânea se tensiona entre uma perspectiva e relações ligadas a uma lógica do direito e uma perspectiva de entretenimento e de consumo de produtos e práticas de divertimento.

Nesse sentido, inicio esse item brincando com as palavras, como nos propõe Larrosa (2002), para poder interpelá-las com um sentido ético-estético. Há uma diversidade de maneiras as quais usamos para nomear essa temporalidade da vida: velho, velhice, terceira-idade, envelhecimento. Cada uma dessas noções, tanto esconde quanto revela identidades e formas de visibilidade, condicionando conceitos e preconceitos, provocando a consciência de limites, mas também de possibilidades.

Chamo, pois, atenção para diferentes formas de conceituar a velhice, assinalando que cada uma dessas maneiras de nomear a velhice expressa, também, formas de classificar a condição humana, produzindo hierarquias e, necessariamente, relações de 
poder. Todavia, esse olhar se justifica menos como signo estruturante da vida social, mas pelo movimento e pelas relações que provoca, no sentido das percepções e experiências que mobiliza em nós e nos empurra cotidianamente a encontrar novos caminhos.

Voltando o olhar para nossa condição humana, quem de nós nunca sentiu algum tipo de medo ou angústia com a velocidade em que o tempo passa, obrigando-nos abrir mão de qualquer ilusão de controle ou poder? Na intensidade que a vida nos dispõe, quem nunca, ao mirar cotidianamente espelhos nunca se perguntou: "velho, eu!?"” De fato, no contexto e nos modos de relação social em que vivemos e nos compartilhamos, produzimos cotidianamente formas de representação sobre o mundo e sobre nós mesmo, positiva e negativamente, que de um jeito ou de outro nos deixam alguma marca.

Quando as pessoas expressam a percepção que fazem de si mesmas, raramente ouvimos alguém dizer que é, e mais, que quer ser velho, ou reconhecido como velho. Ser velho/ficar velho, nas formas e expectativas pautadas nos valores da sociedade ocidental moderna, tornou-se uma expressão pejorativa. Ser velho/ficar velho entrelaçou-se ao signo do descartável, do fora de moda, do que caiu em desuso, do obsoleto, do superado, daquele que supostamente não trabalha e, por isso, não produz. Expressão daquele ou daquilo que não tem mais uso, utilidade e, por isso, sem vida. E assim vamos aceitando mais e mais formas de nos nomear e inevitavelmente de nos classificar: encostados, inativos, aposentados, são também exemplos de alguns dos rótulos que atribuímos a nós mesmos.

É obvio que, dessa perspectiva, ninguém quer ser velho, como se fosse um peso,

3 Para aprofundar essa temática sugiro a leitura da dissertação de Mestrado "Eu, velho? Velhice e Imagens corporais”, de Simone Mendonça Welling, defendida no Programa de Pós-Graduação em Psicologia da PUC-Minas, em 2009, sob orientação de Márcia Stengel. 
algo estático e, com o pesar da expressão, um tempo à espera da morte. O problema, ou melhor, o inevitável é que ser velho é uma condição da nossa humanidade, que constitui a completude de nossa existência. Somos temporalidade, processo e transformação. Mais vale a advertência de Calvino (1990) quando nos lembra da cidade de Leónia, que se refaz todas as manhã; onde o lixo cresce em substância e se amontoa; bastando que uma lata, um velho pneu ou um garrafão rebole para que uma avalanche aconteça.

Querer parar a vida é também abdicar da própria vida! Sempre me impressionou a história de uma famosa atriz de Hollywood que aos trinta e poucos anos se escondeu atrás de grandes óculos escuros e chapéus e nunca mais mostrou seu rosto em público para que fosse conservada, aos olhares externos, a beleza da flor de sua juventude. E quem disse que era essa a beleza que interessava às pessoas que a admiravam; e que interessa à nossa humanidade? Acompanhamos cotidianamente pessoas publicamente influentes, especialmente pelo grande poder que as mídias desempenham, buscando a toda prova passar uma imagem de jovialidade, que reforça modelos de suposta beleza, saúde, felicidade, sucesso, entre tantas outras aparências que de um jeito ou de outro acabam por influenciar crianças, jovens e até mesmo os velhos.

Ser velho não é uma questão de desejo (ou fracasso) individual como a sociedade moderna ocidental nos ensinou a pensar. Como se cada condição de existência fosse um produto que podemos escolher, comprar ou rejeitar. Como a infância, ou mesmo a juventude, ser velho faz parte da nossa existência. O tempo, também, não é uma sucessão de estágios lineares que um após o outro se substituem, sempre deixando algo para trás menos evoluído ou jogando fora o desgastado e o descartável. O pior é quando percebemos que, como objetos, nós é que vamos ser deixado para traz porque, supostamente, ao invés de evoluir, passamos a involuir. Quem 
de nós nunca usou ou escutou expressões como: já estou descendo a montanha/ladeira, ou já estou mais para lá do que para cá?

Todavia, quando buscamos conhecer a posição social do velho em outras formas de expressão das relações sociais, é interessante recuperar outras maneiras de conceber, reconhecer e, sobretudo, praticar o ser velho como posição social. Há contextos como em alguns povos indígenas, ou em comunidades andinas ou em alguns países orientais (ainda que também permeado de tensões e contradições) onde o velho é mais que um guardião, mas a própria revelação da tradição, da prática da sabedoria, do sagrado, das lembranças, da identidade compartilhada; alguém a ser exaltado, respeitado, reverenciado como possibilidade de produção da vida coletiva em uma posição a mais qualificada em dignidade, capaz de tornar possível a ligação presente-passado-futuro; o encarnado e o transcendente, a memória material e o vínculo com o divino.

Ainda que saibamos que as representações sociais são diversas, e nos fornecem imagens ora as mais belas ora as mais restritivas do que é ser velho e envelhecer no contexto contemporâneo; sabemos que a vida não é uma questão de escolher quais signos iremos compartilhar para garantir formas dignas de existência social. Cabe-nos atentar para as práticas que cotidianamente sustentam e alimentam aquilo que de fato somos e fazemos com cada um nós. As práticas constituem não só as relações, mas seus signos e sentidos; e não o contrário. Todavia é importante prestarmos atenção às noções e visibilidades que temos produzido para nós mesmos. Proponho, como primeiro movimento, dar relevo a duas dessas noções: Terceira Idade e Envelhecimento, com suas possibilidades e também paradoxos.

Em nosso contexto contemporâneo inventamos a noção de Terceira Idade. "Terceira" pode trazer diferentes perspectivas. Em algumas práticas nomeamos 
"terceira" quando queremos buscar alternativas às polarizações fragmentadoras. Por exemplo, politicamente falamos em uma terceira via para ampliar qualitativamente as relações entre o estado e a sociedade civil; poeticamente, Guimarães Rosa nos provoca uma sensibilidade e atenção para uma "terceira margem" do rio para nos lembrar ou não nos deixar esquecer que o rio não é apenas um movimento linear em uma única direção, mas, como propõe Ingold (2007) uma malha de entrelaçamentos, linhas, movimentos, seres, energias. Todavia, também, usamos a noção de terceiro como sequência de pontos a serem seguidos. Chegamos ao pondo de demarcar quando começa uma suposta Terceira Idade. É como se fosse uma marca que, a partir de então, entramos definitivamente.

Como ninguém quer como rótulo ou classificação a qualificação de velho, com todos os sentidos pejorativos que produzimos, passamos a apostar em uma positividade da expressão Terceira Idade, especialmente quando ligada a uma noção de cidadania, que acaba enfraquecida quando essa noção é referida em relação à idéia de sujeito consumidor. Assim, se, de um lado, nos afirmamos como sujeitos de direito e passamos a lutar e, de fato, conquistar importantes formas de cidadania como acesso, proteção, instituições e práticas sociais; por outro, quando tomados restritamente como sujeitos consumidores, atribuímos valor a nós mesmos apenas como possibilidade de aquisição dos mais diversos produtos, em especial, atravessados por uma indústria do entretenimento, da saúde e da jovialidade.

Emerge, nesse sentido, um conjunto de instituições, práticas e profissionais especialistas da Terceira Idade que, de um jeito ou de outro, acabam por produzir um mercado de bens simbólicos e materiais. Valendo-se de um suposto tempo disponível que cada vez mais vem se tornando ideal de uma classe média atraída por relações de 
consumo, se tornam cada vez mais vorazes, projetando e alimentando expectativas e desejos.

A Terceira Idade foi descoberta como potencial de consumo e para ela há um mercado atento ao capital proveniente de suas aposentadorias, constantemente alimentando representações e gerando maneiras e formas de ocupar esse tempo, que nem mais é tão nosso assim, de forma idealizadamente prazerosa, saudável e cultural; objetivando uma imagem de "Melhoridade", quando também idealmente, a partir de então, tudo pode ser usufruído. Essa noção, de uma forma geral, busca afirmar um tempo de felicidade, nas mais diversas formas possíveis de aproveitar a vida, onde o compromisso é unicamente consigo mesmo, cada um individualmente esperando alegre e saudavelmente o tempo passar, ou se "preferir", o tempo não passar.

Do ponto de vista da produção cotidiana da vida vamos inventando dicotomias e classificações para nós mesmos, pautando nossas práticas sociais. Assim, quando jovens trabalhamos para nos dar condições de, quando velhos, aproveitar a vida. Temos assistido pessoas desesperadamente trabalhando, quando não exclusivamente para sua sobrevivência e de sua família, cada vez mais para juntar dinheiro, acumular bens, pagar aposentadoria privada, à espera de um dia, quando aposentados poderem aproveitar a vida e poderem alcançar uma tão desejada felicidade.

Enquanto isso, alguns sequer percebem que os filhos cresceram e, muitas vezes, devolvem com a mesma frieza as relações que receberam. Em outros casos vão aumentando as estatísticas de infarto, câncer, diabetes, esquizofrenia, síndrome do pânico e tantos outros processos de adoecimento que, supostamente para evitar, criamos as mais diversas panacéias, das dietas às ginásticas, dos remédios aos tratamentos preventivos, que os planos de saúde, até isso, resolveram fiscalizar: têm-se uma vida 
saudável o suficiente para merecermos desconto em nosso plano de saúde. Seja como criança, ou como jovens ou como velhos continuamente se projeta (ou projetamos) relações que a todos menorizam.

Entretanto, também sabemos que se como representação essa é uma imagem supostamente positiva, pouco a pouco, vai se tornando uma ditadura, especialmente por que isso não se revela como condição universal, e nem mesmo expressão da maioria. $\mathrm{Na}$ verdade, isso se tornou muito mais uma imagem a ser perseguida e mantida, mesmo que poucas vezes vivenciada. E pior, acabamos sendo responsabilizados individualmente pelas condições de nossos adoecimentos ${ }^{4}$.

De outra perspectiva, mesmo que soe paradoxal, gosto da noção de envelhecimento. Revela que a vida é processo, é transformação, é movimento. Sussurranos que não temos o controle de tudo e por isso precisamos aprender a conversar com a vida. Assim como, quando crianças, precisamos aprender a nos equilibrar, andar, escrever, ler, compreender o mundo que nos cerca, também com o passar do tempo precisamos constituir habilidades de dialogar com a vida para que possamos saboreá-la, usufruí-la com mais vagar, calma, paciência, sabedoria.

Envelhecer é também reconhecer que as coisas se transformam e nos transformamos junto com elas. No sentido proposto por Tim Ingold (2011), dizer que as coisas nos transformam é afirmar que humanamente nos tornamos, a cada dia, mais sensíveis e atentos. Nesse sentido, se também somos o mundo e a vida que nos cerca, se somos cada coisa que constitui nossa existência, estar atento à vida é, sobretudo, estarmos atentos e sensíveis a nós mesmos.

Todavia, essa é uma concepção que precisa ser melhor compreendida sob o risco

4 Sugiro leitura do texto de Alex Branco Fraga (2003), A Boa forma de João e o estilo de vida de Fernanda. 
de se tornar também idealizada e romantizada. Sabemos que as tramas da vida são entrelaçadas em muitas tensões. Nos signos da modernidade, como assinala Beatiz Sarlo (2000), elegemos o ser jovem como um ideal. Jovem como sinônimo de potente, ágil, produtivo, eficiente, veloz, saudável; e queremos prolongar este suposto estado ad infinitum. Mas para isso vivemos um paradoxo. Ao mesmo tempo em que queremos parar o tempo e, para isso, entre medicamentos e cirurgias, experimentamos as mais diversas intervenções no corpo, queremos viver cada vez mais como se pudéssemos gozar de um ser jovem eternamente. Há séculos buscamos a pílula da eterna juventude. Revestidos em um discurso cientificista (nem tão científico assim, ou de uma ciência pouco atenta e sensível a uma vida que é dinâmica), confundimos qualidade de vida com quantidade de vida, buscando formas de manutenção da jovialidade como sinônimo de saúde.

A imagem que circula, especialmente nos discursos midiáticos, é que não queremos envelhecer, não queremos que o tempo passe. Queremos, se possível, nos congelar, para acordar em um futuro distante, de preferência jovem, bonito, saudável e com muito dinheiro. Minha história, memórias, relações, pessoas, o mundo que recebemos de presente para com ele aprendermos a nos relacionar se tornou mero acessório, detalhe dispensável.

Cabe, pois, trazer à nossa reflexão um princípio fundamental: nossa integridade; o que implica compreendermos a riqueza de nossa totalidade relacional. Não sou uma individualidade isolada e fragmentada do mundo. Sou processo de individuação justamente porque sou minhas relações, com tudo e com todos que nos envolvem, no sentido proposto por Gilbert Simondon ${ }^{5}$, implicando a inclusão de objetos, paisagens,

\footnotetext{
${ }^{5}$ Simondom apud Liliana da Escóssia, 1999, p. 91.
} 
odores, sons, enfim, a inclusão do mundo, compondo-nos junto com o mundo, reinventando o mundo e a nós mesmos.

Nesse sentido, ser integro, integrado ao processo dinâmico da vida, como propõe Ingold (2011), é habitar um mundo do qual fazemos parte, tocando e sendo tocados por ele, em um pulsar da vida cheio de esperança e responsabilidade. Desse ponto de vista, desdobrarei reflexões sobre o envelhecer como condição de estarmos vivos e nesse sentido relacionar uma noção de participação na cotidianeidade da produção de nossa condição sempre social porque relacional e, nesse contexto, propor um entendimento da importância de retomarmos um olhar do mundo pela lente do Lazer, propondo reencontrar a centralidade inventiva da vida em sua plena condição (po)ética.

\section{Vida como processo, envelhecimento como movimento e relação.}

Busquei até o momento sobressair uma compreensão de que a vida não se constitui em uma individualidade abstrata, como se cada um fosse responsável por conseguir, adquirir, comprar individualmente objetos ou representações, expectativas e ideais que supomos, um dia, se tornarão realidade. A vida é processo, movimento, transformação e invenção permanente.

Indago como buscar, juntos, "abrir caminho", para uma velhice que não é do outro ou minha isoladamente, mas uma condição relacional que nos envolve todos nós? Proponho, nesse sentido, alinhar-me a uma pergunta chave: afinal, o é estar vivo, na temporalidade relacional que somos, lidando com o mundo cada vez com mais qualidade, não necessariamente quantidade, com cada vez mais sensibilidade, não necessariamente eficiência? Para Ingold (2011, p. 162), as pessoas crescem em

\footnotetext{
${ }^{6}$ Tradução livre da noção de Wayfaring proposta por Ingold (2011). Para Ingold (p.162), abrir caminho não é seguir um roteiro rígido, mas negociar o caminho através do mundo, sendo por isso um movimento de compreensão.
} 
conhecimento tanto quanto o experimentam.

Para desenvolver esse olhar, tenho buscado me fundamentar no diálogo com os campos de conhecimento da Educação e da Antropologia, no sentido de compreender melhor nossos processos de tornarmo-nos seres humanos envolvidos na rica diversidade que constitui a vida em que a cada dia nos desenvolvemos, nos ampliamos em habilidades e sabedoria, nos aprimorando nos processos compartilhados do viver. Nessa perspectiva, uma noção que tem ganhado centralidade em minhas abordagens é a noção de aprender, especialmente no sentido proposto por Jean Lave (1993). Arrisco dizer que viver é sinônimo de aprender. Este é o grande desafio que nos coloco, inspirado no Antropólogo Tim Ingold: "aprender a aprender, a cada dia, cada vez mais e melhor"7. Aprender porque a vida nos desafia e nos pede encontrar soluções, porque cada circunstância é diferente, e entrelaça novos elementos, pessoas, situações, climas, artefatos, lugares, paisagens, superfícies materiais ... desafios.

Como pesquisador, tenho buscado compreender as crianças e a infância como temporalidades da vida. Todavia, estudar a infância, só se justifica como possibilidade de melhor entendimento de nossa condição humana. Não acredito em estudos que se fecham em sujeitos específicos, isolados de sua expressão relacional. Só concebo a criança em relação. As crianças partilham um lugar nas relações sociais envolvidas por pessoas adultas e velhas, outras crianças, plantas, bichos, coisas. As crianças precisam do adulto, precisam da tradição, precisam das práticas de lembrança. Assim como nós adultos precisamos do renascimento, da inventividade, da imaginação como parte indissociável da realidade.

Cabe, ainda, afirmar ou perceber que todos nós carregamos em nossos corpos as

\footnotetext{
7 Tradução proposta por Ana Maria Rabelo Gomes ao título da palestra ministrada por Tim Ingold na Faculdade de Educação da UFMG, no dia 05/10/2011.
} 
marcas de uma humanidade que, no sentido de Benjamin (1987), permanentemente se entrelaça como presente-passado-futuro. A criança e o velho, ao lado de expressarem pessoas e uma condição humana concreta e encarnada é também uma metáfora de nosso ser total. Trago em meu corpo-mente a lembrança viva de uma infância que me acompanha, alimenta meus sonhos, medos, afetos, necessidades, possibilidades e esperança sempre renovada.

O velho não é apenas um outro diferente de mim revelando uma humanidade que eu desejaria evitar. A velhice também se inscreve no meu corpo, se revelando não como adágio, mas como possibilidade. Nessa perspectiva certamente é fundamental continuarmos nos indagando o sentido da vida. O que quero para mim e para o meu filho não existe desintegrado do que quero para todas as crianças e para todas as pessoas: dignidade. As crianças e os velhos são enigmáticos porque a vida é enigmática, sempre aberta e dinâmica. No sentido de Maurice Merleau-Ponty (1999 [1945]), a vida é enigmática porque se compõe com o que nos é externo, com o qual nos relacionamos. Nesse sentido, nem crianças, nem velhos são estranhos a mim. Fazem parte de minha humanidade.

Pretendo assinalar a direção de minhas palavras e afirmar mais que uma intenção, mas uma ação que assume a responsabilidade de juntos compreendermos a riqueza da vida humana em sua ampla temporalidade, em um movimento sempre e inevitavelmente aberto para o novo. De certo, isto não é o mesmo que afirmar uma idéia de novidade como aquela que descarta o que se tornou obsoleto. Mas de reconhecer que é novo porque estamos vivos, em um movimento de vida sempre criativo, produtivo e para o qual precisamos estar atentos e sensíveis: às pessoas, à natureza, às relações, aos animais não-humanos, à vida em sua plenitude. 
Com as reflexões feitas até aqui, pretendi anunciar as cores e os sabores que proponho para compreendermos o tema do Lazer e o sentido que procuro enfatizar por Participação Social.

\section{Lazer como forma de participação e produção poética da vida social}

O Lazer, neste texto, se anuncia como uma lente, um olhar atento ao processo de envolvimento, participação e percepção do mundo e da vida, que é sempre movimento, que é sempre inventiva. Sem a intenção de minimizar formas de expressão objetivas e instrumentais que constituem a vida, proponho me aproximar de processos e práticas que se reconhecem sensíveis; e buscam dar centralidade às relações e processos éticos e estéticos, à arte e ao corpo, ao ritual e ao festivo na partilha e produção cotidiana de nossas experiências sociais. ${ }^{8}$

Em um entendimento corrente, o Lazer muitas vezes é concebido como um objeto, um produto, que na maioria das vezes só se é compreendido como contraponto às práticas sociais que na modernidade passaram a dar uma suposta centralidade à produção material da vida. Assim, de forma fragmentada, reiteramos a dicotomia entre trabalho e lazer; ciência e arte; tempo institucionalizado e tempo livre; seriedade e diversão; produção e consumo; eficiência e entretenimento; previsível e espontâneo entre tantas separações que menorizam a riqueza de nossas formas de expressão. $\mathrm{O}$ Lazer também se associou a uma indústria da diversão, do prazer, da felicidade e da jovialidade.

Todavia, o lazer como um processo de relação com o mundo é maior que isso.

\footnotetext{
${ }^{8}$ Não é proposta desse texto a apresentação ou defesa de um conceito de Lazer. Mesmo porque isto tem sido feito de forma bastante coerente e consistente ao longo das três últimas décadas por diferentes estudiosos como Nelson Marcelino (1987; 1995; 2006), Christianne Gomes (2004; 2008); Helder Isayama (2004 ); Victor Melo (2006); Fernando Mascarenhas (2007), entre outros.
} 
Proponho pensar que a noção de Lazer provoca, ou nos convida a fazer, uma inversão na lente do mundo, recolocando em sua centralidade expressões e relações que na história da civilização ocidental foi progressivamente relegada a sua periferia, como a arte, a imaginação, o sagrado, o corpo, a música, a dança, a poesia, etc .

Nessa perspectiva propositalmente faço um movimento que nos convida fluir uma maneira de olhar para a vida de uma forma mais (po)ética. Não é à toa que correntemente usamos a expressão "Arte de Viver”. Cabe aqui, pois, mais uma vez recorrendo a Merleau-Ponty, o convite para pensar a vida como arte. Assim, compreendendo a vida como arte, em um sentido generativo, criativo, generoso, encarnado e relacional, isto me remete o entendimento (que se tomado de forma aligeirada, pode soar simplista), de que participação é indissociável de se estar vivo. Do contrário, é como se quiséssemos, como nos provoca o antropólogo Tim Ingold, compreender o peixe e seu fluir separado do rio ou do oceano, compreender o voo do pássaro separando-o do $a r^{9}$. Nessa perspectiva, participamos como seres sociais porque habitamos um mundo em movimento, sempre em transformação e nele, também, estamos e somos constante transformação, criação e geração de vida.

De certo, isso não desfaz a importância de refletirmos sobre as maneiras que nós seres humanos nos constituímos como histórias de legitimidade, valor, dignidade, integridade, ou em muitas circunstâncias, o contrário de tudo isso, menorizando nossa condição humana. Por isso, a noção de participação aqui proposta também nos desafia ampliar os sentidos que temos atribuído à noção de social, que é maior que a noção de sociedade e transcende as relações pessoa-pessoa, configuradas em instituições, contextos e situações específicas.

\footnotetext{
${ }^{9}$ Imagens usadas por Ingold durante palestra na UFMG, em outubro de 2011, para exemplificar a noção de malha (meshwork), diferenciando da noção de rede (network) como interconexão entre pontos.
} 
Reivindico uma noção de social que solicita uma atenção à riqueza relacional que a vida constantemente revela e nos coloca em relação com outros humanos. Mas também com os animais não humanos, com as plantas, com uma infinidade de objetos e artefatos que compõem a rica paisagem que se revela no movimento do mundo, nos provocando prestar atenção às sutilezas também da terra, do ar, da água, e tudo, tudo ao nosso redor. No sentido proposto por Ingold (2003, p. 117), estamos tratando aqui de uma forma de sociabilidade compreendida como uma habilidade de agir mediante uma história de envolvimentos mútuos, capaz de remeter a uma compreensão humana que comece a partir da premissa de nosso comprometimento com o mundo, em vez do nosso afastamento dele. Sociabilidade como um campo relacional, produzindo sensibilidades e disposições.

Assim, ao propor uma reflexão sobre o tema do Lazer e da Participação Social busco compor um desenho para nossas formas de viver. Enfatizo a poesia de estarmos vivos, entrelaçados em um mundo extremamente rico e em permanente movimento, transformando-nos a cada dia, sensíveis e atentos a um mundo em transformação, requerendo de nós o cuidado, a atenção, a sensibilidade, a responsabilidade, a percepção e a ação; em outras palavras, sabedoria para ampliarmos nossas aprendizagens e formas de participação.

Ao pensar uma velhice que é nossa, não de um outro diferente de mim; invariavelmente vejo-me remetido ao belíssimo livro de Ecléa Bosi (1979), Memória e Sociedade: lembrança de velhos, e não menos brilhante apresentação escrita pela filósofa Marilena Chaui, um pouco por sua beleza, um pouco por sua veracidade, mas sobretudo porque desafia ir além, saindo de lugares comuns, indignando-nos com quaisquer estruturações, determinações e aprisionamentos da vida e das relações. 
Chaui (1979), após um conjunto de reflexões e denúncias fundamentais sobre a vida que passamos a compartilhar no contexto das sociedades capitalistas com seus princípios de eficiência, competição, velocidade e novidade; nos desafia com uma imagem de envelhecimento como processo de desvalorização e deslegitimação de nossa força de produção, de nossos saberes e de nossas habilidades técnicas: caso permaneçamos assistindo passiveis nossas vidas serem roubadas, esvaziando nossa dignidade.

$\mathrm{Na}$ linguagem fílmica essa imagem também me remete ao belo filme Banhos, do diretor chinês Yang Zhang que nos transporta a um tradicional bairro de Pequim que está em processo de demolição para dar lugar a uma região de novos empreendimentos, tecnologias e processos de modernização. Nesse contexto, resiste uma casa de banhos que entrelaça por fios delicados a lembrança de uma tradição de relações e encontros que de uma lógica e temporalidade de amadurecimento e elaboração, com todas as tensões e angústias que inevitavelmente atravessa a vida de cada um de nós, nos provoca um reencontro ético com as exigências de uma outra racionalidade da vida.

De certo o contexto social capitalista, além de provocar transformações materiais em nossas cidades desfazendo e refazendo paisagens, técnicas e relações, reproduz cotidianamente um bombardeio de informações e imagens que enfraquecem nossos sentidos, nossa atenção ao mundo, aos outros e às coisas. Fragiliza nossa imaginação e, com isso, também nossos sonhos e esperanças. Mas é preciso afirmar que a vida é maior. Voltando às reflexões propostas por Marilena Chaui (1979, p.32), ela nos apresenta a seguinte indagação: o que seria necessário para que o velho fosse tratado com dignidade? Em seguida nos traz uma resposta desafiadora: seria necessário que tivesse sido tratado, desde sempre, com dignidade. 
De um lado essa resposta é fundamental, porque nos faz pensar na totalidade da vida. Afinal, nossa condição humana de dignidade e integridade se entrelaça e entrelaça todos. Sou digno em relação. A indignidade do outro é minha também. Por outro lado, essa resposta sempre me deixou um gosto amargo na boca, um sentimento como se já fosse tarde demais. Se a referência for os processos de alienação e a teia da vida for uma representação ideológica que atravessa e desintegra cotidiana e inexoravelmente todos nós, então a vida saiu derrotada. Só nos restaria a morte, a doença, a solidão e o isolamento. Não é uma questão de discordância, teórica ou filosófica. Refiro-me a um sentido que produz o movimento necessário de ir além, provocando-nos descobrir possibilidades para a vida humana.

A pergunta da Marilena Chaui é ainda mais desafiadora. Qual o sentido que se desdobra da resposta: desde sempre sermos tratados com dignidade. Eu, aligeiradamente, arriscaria afirmar o que compreendo não ser dignidade: o isolamento não é dignidade ${ }^{10}$; relacionar-se apenas com pares imediatos não é dignidade, como, por exemplo, criança que só se relaciona com criança, velho com velho, negro com negro, homossexual com homossexual, etc. Como assinala o filósofo Bakhtin (1988), preciso de um exotopos, ou seja um outro lugar diferente do meu, ou o poeta Arnaldo Antunes ${ }^{11}$ quando canta, seu olhar melhora o meu. Cabe, pois, abrirmos caminho para dar materialidade a essa vida que inevitavelmente brota por entre brechas e fendas.

Por exemplo, pensar a educação das crianças é algo que me fascina. Quando olhamos ao redor a riqueza da vida, ficamos nos perguntando não apenas sobre os conhecimentos que compartilhamos com as crianças, mas, sobretudo, as maneiras como o fazemos. De certo, é fundamental estarmos atentos a uma infinidade de histórias

\footnotetext{
${ }^{10}$ Como lembra Todorov (1999, p. 225), o isolamento dos sujeitos constitui uma das primeiras formas de renúncia à autonomia.

${ }^{11}$ Paulo Tatit e Arnaldo Antunes, O Seu Olhar. Álbum Ninguém, 1995.
} 
de barbáries que constantemente expomos à nossas crianças na forma de guerras e violências de todo tipo estampadas nas televisões e até mesmo nos brinquedos. Como nos lembram Bazílio e Kramer (2003, p. 79),

[...] o reconhecimento social da criança tem levado muitos adultos a abdicarem de seu papel. Parece que usam uma concepção de "infância como sujeito" como desculpa para não colocar regras, não expressar seu ponto de vista, não se posicionar. O lugar do adulto fica desocupado, como se para a criança ocupar um lugar o adulto precisasse desocupar o seu, o que revela uma distorção profunda do sentido de autoridade.

Diferentemente disso, temos tantas coisas e práticas sociais de dignidade a compartilhar. Quando penso a escola também me ressinto de uma abertura maior para a vida. Por exemplo, sempre me pergunto por que desenho tão mal? Será porque não tenho dom ou aptidão? O desenho, a não ser como conteúdo de matemática, nas aulas de geometria, nunca teve muita importância como sensibilidade e conhecimento escolar.

Sem desvalorizar a também importância de conhecimentos como ler e escrever, matemática e ciências, o problema é que estes conhecimentos sempre tiveram uma centralidade abstrata que poucas vezes flui para fora da escola e nos possibilita enriquecer nossas relações com a vida. Sem menorizar a importância desses conhecimentos, há muitas outras formas de escritas que também se produzem como tradição. Deixamos rastros na materialidade da vida como narrativa de um mundo que se expressa em pinturas, em esculturas, nas danças, na música, nas muitas formas que se revelam em nossos corpos como arte e em nossas relações de cuidado, uns com os outros e com a natureza. Como uma mãe que cotidianamente dá lições de cuidado, pode sentir-se sem valor na produção material da vida, ou ter sua prática social menorizada? Quanta poesia há na jardinagem, no cozinhar, na prática da parteira? Quantas lições de habilidade, sensibilidade e engajamento na vida? 
Essa provocação vem no sentido de nos ajudar a repensar a centralidade que atribuímos aos conhecimentos que nos habilitam a responder aos desafios do mundo. Proponho pensar a centralidade da arte, do corpo, do movimento, do cotidiano, do sensível na escola, assim como quero provocar a centralidade da arte, do movimento e do sensível na vida, desafiando nossa atenção e cuidado com o mundo. Não tenho dúvidas de que é a nossa habilidade de atenção o que nos torna capazes de perceber, potencializando outras ações como ler, escrever, codificar e decodificar matematicamente e, até mesmo, compreender o mundo cientificamente. Vivemos cotidianamente o desafio de elaborar uma Ciência aberta, atenta à dinâmica da vida; não uma ciência que está o tempo todo buscando estatizar a vida para poder conhecê-la. Volto ao antropólogo Tim Ingold (2011) no sentido do desafio que ele nos coloca de buscarmos compreender e aprender um mundo que está em movimento.

Nesse ponto quero enfatizar um entendimento de arte compreendida como um fazer sensível, atento e habilidoso aos desafios da vida, nas relações com a diversidade de suas materialidades e superfícies. Cabe, pois, retomar uma noção cara a muitos filósofos que é a noção de experiência. Acostumamos a ver o mundo a partir de uma lógica cartesiana que substituiu a noção de experiência pela noção de experimento, e nos permitimos ser afastados do mundo sensível, que passou a ser mensurado e aferido por instrumentos externos ao nosso corpo e por isso livre de nossas supostas fraquezas, e instabilidades de nossa subjetividade.

O mundo deixou de ser tocado em nossa totalidade que é corpórea e, assim, deixamos de habitar o mundo, deixamos de habitar nós mesmos e, em nosso lugar, substituímo-nos por objetos cada vez mais precisos e sofisticados que nos perspectivam, de forma abstrata e imóvel, encontrar a verdade "científica" da vida e do viver. Dessa 
perspectiva, nós também nos tornamos instrumentos. E como todo instrumento obsoleto, ou que vai perdendo a aferição é descartado e trocado por outro mais novo, eficiente e ajustado à lógica objetiva de um mundo mensurável e objetivável, nós também vamos sendo deslegitimado como saber, e a vida parecer se menorizar como sabedoria. Todavia, continuamos sabendo que a vida é maior.

Por isso mais uma vez refiro-me à admiração que tenho pelas crianças. Mesmo que os processos de escolarização, as instituições, o cotidiano gerem processos e relações que reproduzem a mecanização da vida, quando observamos as crianças e suas maneiras de se relacionar com o mundo e com as coisas muitas lições podem ser aprendidas. Nesse sentido, também leio o desafio da Chaui (1979) como a importância de também, como adultos, aprendermos com as crianças. Achamos que sabemos mais que as crianças. Não é bem assim. Crianças e adultos sabem coisas diferentes. Os jovens acham que podem mais que os velhos. Engano. Podemos coisas diferentes, que não tenho dúvidas estão mutuamente entrelaçadas.

Há na criança formas de saber muito interessantes. Tenho me interessado pelo brincar como processo de religação entre o real e o imaginário. As crianças são capazes de repetir e imitar o mundo adulto e a tradição sem que o façam de forma sempre igual, mas o fazem de forma improvisada e criativa, reinventando, remontando, virando o mundo de cabeça para baixo. No sentido de Benjamin (1984), muitas vezes, reescrevendo a história com o lixo da história. Todavia, tenho compreendido que isso não é uma característica da criança, mas a nossa condição humana, encarnada em um mundo em constante movimento

É nessa perspectiva que busco, mais uma vez, enfatizar a importância da centralidade da arte, do corpo, do movimento na geração de todo e qualquer 
conhecimento e processo de aprendizagem. E aqui o sentido de Lazer como uma forma de engajamento e também como forma de produção e participação social: no fazer artístico, como presença sensível, atenta e encarnada, produzimos o mundo e produzimos a nós mesmo; compartilhamos a produção da vida e constituímo-nos sociais.

Essa é a aposta, que desse olhar se desdobra, para a educação das crianças, essa é uma aposta para o exercício de nossa presença cotidiana nesse mundo que habitamos: aprendermos, a cada dia, a agir e nos relacionar de forma atenta e sensível, cada vez mais reconhecendo-nos atentos e sensíveis. Atentos e afetados pelo mundo; sensíveis e afetando o mundo. Por isso, como participação social, proponho enfatizar nossa habilidade de envolvermo-nos no mundo, com todos e com tudo ao nosso redor. Desafio à expressão de uma presença política mais intensa do que se reconhecer no processo de se co-responsabilizar com o movimento e geração permanente da vida. Essa é, também, a minha aposta, para as crianças, para os jovens e para os velhos; de empenharmo-nos em nossa tarefa de juntos compartilharmos habilidades de estar juntos no mundo, vivendo, a cada dia, melhor.

Ao fazer tal afirmação cometo a ousadia de colocar-me no lugar de pessoas mais velhas buscando harmonizar-me com suas prolongadas histórias de relações com o mundo, com a natureza, com as pessoas. Vejo-me entre situações distintas que observo cotidianamente. Percebo que as pessoas experimentam seus processos de envelhecimento de maneiras diferentes. Algumas preferem o contexto de suas casas e a intimidade de suas vidas. Outras querem sair, se relacionar e sentir-se mais joviais. Algumas pessoas querem viver o direito de serem deixadas em paz, não querem fazer parte de grupos, fazer viagens e se divertir. De certo, nas miudezas da vida há uma 
riqueza de possibilidades infinitas de relação. Outras querem sair de suas casas, conhecer pessoas, viajar, fazer ginástica, ir a festa, sentir-se saudáveis.

É necessário, de certo, tomarmos o cuidado para não simplificarmos as relações. Muitas vezes nossos processos de solidão revelam também processos de adoecimento. Entretanto, por que não podemos viver com mais silêncio, mais lentidão, mais contemplação? Também me assusta uma certa ditadura da felicidade e da eterna juventude, como se obrigatoriamente e a todo momento tivéssemos a obrigação de parecermos alegres e felizes. Dores, angústias, tristezas, estar sozinho também faz parte dos nossos processos de elaboração de nós mesmos. Preciso do outro, mas também preciso de mim mesmo, perceber-me, sentir-me, usufruir-me, confrontar-me com o que tenho de bom e com aquilo que me assusta em mim e faz emergir nossos lados sombrios.

\section{Para continuar e ir além: Lazer como produção poética e compartilhada da vida}

Retomo, nesse ponto, o tema do Lazer como possibilidade de "trazer de volta" a poesia da vida e, mais uma vez, brincar com as palavras, parafraseando Ingold (2011), dizendo que precisamos "trazer a vida de volta à vida". Pergunto mais uma vez: afinal, o que é ser velho? Quem são estes a quem nomeamos velhos? O que podem os velhos?

Nem sempre o que nos limita nos restringe. Ao contrário, muitas vezes o que nos constrange é o que nos potencializa, é o que nos provoca mostrar nossas possibilidades. Esse, certamente, poderia ser um sentido interessante para a vivência do Lazer: experiências que nos possibilitassem viver, conhecer e ampliar os potenciais da vida humana, nossa capacidade de movimento e relação, conosco, com o outro e com o 
mundo.

Gosto de apostar na relação entre envelhecimento e processo de constituição de sabedoria. Nas palavras de Roland Barthes (2004 [1978]), uma riqueza de conhecimentos que nos possibilite reivindicar um pouco de saber e o máximo de sabor possível. Mas o que é sabor? O que é saborear a vida? Sabor, saber, sabedoria implica repensarmos a velocidade da modernidade que reiteramos a cada dia. É preciso pensar o sentido de eficiência.

O que queremos como expressão: qualidade ou quantidade? É preciso repensarmos tecnologias que implicam a substituição do fazer com as mãos, com os pés, com todos os sentidos do corpo, e irmos além de uma forma de viver que resulta em parar de andar e de nos relacionarmos com a materialidade da vida, remetendo-nos a uma vida sentada e imóvel. As virtualidades substituíram nossos encontros de carne e alma. De certo que isso não vai ser compreendido como deixar de usufruir todas as tecnologias que fomos capazes de humanamente inventar: computador, internet, celular, entre muitas outras.

Não é uma questão de negar a importância do novo, da tecnologia, da inovação. Mas quem é que vai lembrar aos nossos netos a poesia de escrever uma carta de amor que demorava uma semana para chegar; nossos amados demoravam dois dias para abrir acariciando e abraçando o envelope, mais um tempo para escrever uma resposta, um tempo para ter coragem de enviar, um tempo para chegar, um tempo para (se) abrir ... um tempo para o amor se constituir, realizar, crescer e nos transformar. Para que(m) tanta pressa?

Nessa perspectiva é que precisamos, como companheiros de viagem, repensar o que esperamos dos velhos, qual o lugar e tempo que os temos colocado e possibilitado 
ocupar um sentido na produção da vida. Viveremos melhor se todos formos jovens e joviais? Todavia, deixar de reconhecer o direito de acesso à cultura, à cidade, a condições de saúde dignas, às práticas corporais, etc. seria um equívoco muito grande.

É importante o direito a fazer ginástica, musculação, práticas de caminhada, práticas corporais como Yoga, Tai Chi, Li Gong, esportes, dança, experiências culturais como teatro, música, dança, orquestras sinfônicas, possibilidades de fazer pequenas e grande viagens, conhecer lugares, pessoas, relações, outros modos de vida. Tudo isso, inegavelmente, é um direito do qual ninguém pode ser privado. Por isso a Marilena Chaui (1979) nos lembra que precisamos viver com dignidade desde sempre e não apenas com o sentido de recuperar o tempo perdido. Não para ocupar o tempo, mas pelo direito de estarmos integrados com toda a riqueza que faz parte dessa história de conhecimentos e práticas humanas que produzimos e escrevemos juntos.

Mas essa riqueza relacional também é sutil, e não menos importante. Igualmente importante é o maravilhoso espetáculo de um dia lindo, do nascer e do por do sol, da relação que podemos ter com a terra, com a água, com as plantas; a admiração com o céu, seu movimento e suas transformações. O cuidado com os seres humanos, as plantas, os animais, a terra como um todo. É preciso afinarmos nosso olhar, nosso tocar, escutar, cheirar, ouvir a riqueza da vida.

Fazer "atividades" (no sentido de agir no mundo) é muito mais que como ouvíamos na década de 1970, uma idéia de “mexa-se” e ficará saudável. Proponho um entendimento de ação como sinônimo de habilidades para perceber e sentir as coisas do mundo como movimento e processo de relação. Pode parecer uma bobagem, mas participar é um verbo, uma ação, um processo e não um substantivo objetivado a ser adquirido e/ou garantido por outro. Participar é fazer emergir uma consciência 
encarnada no mundo. Essa é nossa condição, processo e possibilidade de vida.

O que aqui, como reflexão, se reivindica para a relação lazer e envelhecimento é uma riqueza de processos de envolvimento na vida. Produzir como sinônimo de viver. É impossível dissociar o estar vivo e o ser produtivo. Aposto, pois, na relação trabalhovida, entendida aqui em seu sentido maior: a vida é produtiva. É nessa perspectiva que indago ao Lazer e a nós mesmos sobre a riqueza de engajamentos, envolvimentos, entrelaçamentos que temos sido desafiados cotidianamente a compartilhar: na relação com a família, com as artes, com os animais, com os outros seres humanos, com a natureza, ou seja, com o cuidado com o mundo?

Essa é a centralidade de minha proposta de reflexão sobre o Lazer: provocar um entendimento de participação como ação compartilhada de cuidado, de cuidar-se, de ser cuidado, de deixar-se ser cuidado, de permitir-se cuidar, de compartilhar cuidados: consigo mesmo, com as pessoas, com a natureza, com a vida material. E compreender essa perspectiva como uma ação política encarnada.

\section{REFERÊNCIAS}

BAKHTIN, Mikhail. Marxismo e filosofia da linguagem. 4. ed. São Paulo: Hucitec, 1988.

BARTHES, Roland. Aula. São Paulo: Cultrix, 2004 [1978].

BAZILIO, Luiz; KRAMER, Sonia. Solidariedade em tempos de violência: apontamentos e inquietações. In: BAZÍLIO; KRAMER. Infância, educação e direitos humanos. São Paulo: Cortez, 2003. p. $71-84$.

BENJAMIN, Walter. Obras escolhidas. Magia e técnica, arte e política. São Paulo: 
Brasiliense, 1987. v.1

BENJAMIN, Walter. Reflexões: a criança, o brinquedo, a educação. São Paulo: Summus, 1984.

BOFF, Leonardo. A águia e a galinha: uma metáfora da condição humana. Petrópolis: vozes, 1997.

BOSI, Ecléa. Memória e Sociedade: lembranças de velhos. São Paulo: Companhia das Letras, 1979.

CALVINO, Ítalo. As Cidades Invisíveis. São Paulo: Companhia das Letras, 1990.

CHAUI, Marilena. Apresentação - Os trabalhos da memória. In. BOSI, Eclea. Memória e Sociedade: lembranças de velhos. São Paulo: Companhia das Letras, 1979.

ESCÓSSIA, Liliana da. Relação homem-técnica e processo de individuação. Sergipe: UFS/Fundação Oviêdo Teixeira, 1999.

FRAGA, Alex Branco. A boa forma de João e os estilo de Fernanda. In. LOURA, Guacira et al. Corpo, Gênero e Sexualidade: um debate contemporâneo na educação. Petrópolis: Vozes, 2003.

GOMES, Christianne. Lazer. Concepções. In. GOMES (Org.) Dicionário Crítico do Lazer. Belo Horizonte: Autêntica, 2004.

GOMES, Christianne. Lazer, Trabalho e Educação. Belo Horizonte: UFMG, 2008.

INGOLD, Tim. Being Alive. London: Routledge, 2011.

INGOLD, Tim. Lines: a brief history. London: Routledge, 2007.

INGOLD, Tim. A evolução da sociedade. In. FABIAN, A. C (Org.) Evolução: sociedade, ciência e universo. Bauru: EDUSC, 2003.

ISAYAMA, Helder. Formação Profissional. In. GOMES (Org.) Dicionário Crítico do Lazer. Belo Horizonte: Autêntica, 2004. p. 53 - 96. 
LARROSA, Jorge. Notas sobre a experiência ou o saber da experiência. Revista Brasileira de Educação, n.14, jan-abr, 2002. p. 20 a 28.

LAVE, Jean. The practice of learning. In. CHAIKLIN, S; LAVE, J. (Eds.). Understanding in practice: perspectives on activity and contex. Cambridge: Cambridge University Press, 1993.

MARCELINO, Nelson. Lazer e Humanização. Campinas: Papirus, 1995.

MARCELINO, Nelson. Lazer e Educação. Campinas: Papirus, 1987.

MARCELINO, Nelson. Estudo do Lazer: uma introdução. 3.ed. Campinas: Papirus, 2006.

MASCARENHAS, Fernando. Lazer e utopia: limites e possibilidades de ação política. In. SUASSUNA; AZEVEDO (Org.). Política e Lazer: interesses e perspectivas. Brasília: Thesaurus, 2007. p. $181-210$.

MELO, Victor. A animação cultural: conceitos e propostas. Campinas: Papirus, 2006.

MERLEAU-PONTY, Maurice. Fenomenologia da Percepção. São Paulo: Martins Fontes, 1999 [1945].

SARLO, Beatriz. Cenas da vida pós-moderna: intelectuais, arte e videocultura na Argentina. Rio de Janeiro: Ed. UFRJ, 2000.

TODOROV, Tzvetan. O homem desenraizado. Rio de Janeiro: Record, 1999.

WELLING, Simone M. Eu, velho? Velhice e Imagens corporais. Dissertação ( Mestrado ) - Programa de Pós-Graduação em Psicologia da PUC-Minas, Pontifícia Universidade Católica de Minas Gerais, 2009.

\section{Endereço do Autor:}

José Alfredo Oliveira Debortoli Escola de Educação Física, Fisioterapia e Terapia Ocupaconal/UFMG.

Av. Antônio Carlos, 6627, Pampulha

Belo Horizonte - MG - 31270-901

Endereço Eletrônico: dbortoli@eeffto.ufmg.br 